\title{
Performance of the CryoValve* SG human decellularized pulmonary valve in 342 patients relative to the conventional CryoValve at a mean follow-up of four years
}

\author{
John W. Brown, MD, Ronald C. Elkins, MD, ${ }^{\mathrm{b}}$ David R. Clarke, MD, ${ }^{\mathrm{c}}$ James S. Tweddell, MD, ${ }^{\mathrm{d}}$ \\ Charles B. Huddleston, MD, ${ }^{\mathrm{e}}$ John R. Doty, MD, ${ }^{\mathrm{f}} \mathrm{John}$ W. Fehrenbacher, MD, ${ }^{\mathrm{g}}$ and \\ Johanna J. M. Takkenberg, MD, $\mathrm{PhD}^{\mathrm{h}}$
}

Objective: This study compared clinical outcomes of patients receiving CryoValve SG decellularized pulmonary valves with those of patients receiving conventionally processed CryoValve pulmonary valves.

\begin{abstract}
Methods: All consecutive patients undergoing Ross procedures and right ventricular outflow tract reconstructions with SG valves at 7 institutions (February 2000-November 2005) were assessed retrospectively (193 Ross procedures, 149 right ventricular outflow tract reconstructions). Patient, procedural, and outcome data were compared with those from 1246 conventional implants (665 Ross procedures, 581 right ventricular outflow tract reconstructions). Hemodynamic function was assessed at latest follow-up.
\end{abstract}

Results: Follow-up was complete for $99 \%$ in SG group and $94 \%$ in conventional group, with mean follow-ups of 4.0 years (range, $0-6.7$ years) for SG and 3.7 years (range, 0-6.7 years) for conventional. Five-year cumulative survivals and freedoms from adverse events were comparable between SG and conventional valves. Among patients undergoing Ross procedures, peak gradient at last follow-up was lower with SG valves $(P<.01)$; no difference was observed in the right ventricular outflow tract reconstruction population. Pulmonary insufficiency was significantly reduced with SG valves in patients undergoing both Ross procedures $(P<.01)$ and right ventricular outflow tract reconstructions $(P<.01)$. Valve type was not a significant predictor of valve-related failure in propensity-adjusted analysis of either procedure.

Conclusions: CryoValve SG decellularized pulmonary valves have acceptable clinical outcomes and favorably compare with conventionally processed valves. Improved hemodynamic function observed with SG valves could signify improved long-term outcomes and may be due to the decreased antigenicity of these valves. (J Thorac Cardiovasc Surg 2010;139:339-48)

Earn CME credits at

http://cme.ctsnetjournals.org

Cryopreserved allograft heart valves have been widely used in the repair of a variety of congenital and acquired valvular

\footnotetext{
From Indiana University School of Medicine, ${ }^{a}$ Indianapolis, Ind; University of Oklahoma Health Sciences Center, ${ }^{b}$ Oklahoma City, Okla; The Children's Hospital Heart Institute, ${ }^{\mathrm{c}}$ Denver, Colo; Children's Hospital of Wisconsin, ${ }^{\mathrm{d}}$ Milwaukee, Wis; St Louis Children's Hospital, ${ }^{\mathrm{e}}$ Washington University School of Medicine, St Louis, Mo; Intermountain Medical Center, ${ }^{\mathrm{f}}$ Salt Lake City, Utah; Methodist Hospital of Indiana, ${ }^{\mathrm{g}}$ Indianapolis, Ind; and Erasmus Medical Center, ${ }^{\text {h }}$ Rotterdam, The Netherlands.

Disclosures: This work was funded by CryoLife, Inc, Kennesaw, Ga.

Read at the Thirty-fourth Annual Meeting of The Western Thoracic Surgical Association, Kailua-Kona, Hawaii, June 25-28, 2008.

*Manufactured by CryoLife, Inc, Kennesaw, Ga.

Received for publication June 24, 2008; revisions received April 2, 2009; accepted for publication April 27, 2009.

Address for reprints: John W. Brown, MD, Section of Cardiothoracic Surgery, Indiana University School of Medicine, 545 Barnhill Dr, EH 215, Indianapolis, IN $46202-$ 5123 (E-mail: jobrown@iupui.edu).

0022-5223/\$36.00

Published by Elsevier Inc. on behalf of The American Association for Thoracic Surgery

doi:10.1016/j.jtcvs.2009.04.065
}

lesions and in replacement of the native pulmonary valve during the Ross procedure (pulmonary autograft). Clinical results from the use of cryopreserved allograft heart valves demonstrate excellent hemodynamic performance, resistance to infection, and good durability, especially in the Ross operation. ${ }^{1-7}$ Conventionally processed cryopreserved allografts have been shown to stimulate donor-specific humoral and cellular immune responses, however, which may decrease the durability of conventional cryopreserved valves, especially in younger patients. ${ }^{8-12}$ The CryoValve SG pulmonary allograft valve (SGPV; CryoLife, Inc, Kennesaw, Ga) was developed to reduce the antigenic donor cells that remain after conventional valve processing methods. The SGPV was introduced into clinical use in 2000. Early clinical reports have demonstrated a significant reduction in the immunologic response by recipients of SGPVs as measured by panel-reactive antibody levels relative to recipients of conventional cryopreserved allograft valves. ${ }^{13-16}$

This study evaluated clinical and echocardiographic outcomes of patients receiving SGPVs for either the Ross procedure or right ventricular outflow tract (RVOT) reconstruction. Results from patients with SGPVs were compared with results from the conventionally processed 


$$
\begin{aligned}
& \text { Abbreviations and Acronyms } \\
& \begin{array}{ll}
\text { CI } & =\text { confidence interval } \\
\text { HR } & =\text { hazard ratio } \\
\text { LOR } & =\text { linearized occurrence rate } \\
\text { RVOT } & =\text { right ventricular outflow tract } \\
\text { SGPV } & =\text { CryoValve SG pulmonary allograft valve }
\end{array}
\end{aligned}
$$

cryopreserved CryoValve pulmonary allograft valve (CryoLife). Analyses included propensity-adjusted evaluation of valve-related failure to assess the effect of the SynerGraft process of decellularization (CryoLife) on allograft valve durability.

\section{MATERIALS AND METHODS \\ Participating Institutions and Patient Population}

This was a retrospective, nonrandomized, multicenter cohort analysis involving 7 implanting institutions in the United States. Institutional review board approval for the study was obtained at each institution. All consecutive patients in whom SGPVs were implanted during the Ross procedure or RVOT reconstruction (February 2000-November 2005) were included in the study. Patients who did not consent $(n=2)$ were excluded, resulting in 342 patients subjected to follow-up. Of the 342 patients included in the study, 193 received the SGPV during a Ross operation and 149 during RVOT reconstruction. The participating institutions and corresponding patient enrollment were as follows: University of Oklahoma Health Sciences Center, Oklahoma City, Okla $(n=133)$; Indiana University School of Medicine Hospital, Indianapolis, Ind ( $n=41)$; The Children's Hospital Heart Institute, Denver, Colo $(\mathrm{n}=51)$; Children's Hospital of Wisconsin, Milwaukee, Wis ( $\mathrm{n}=43)$; Washington University, St Louis, Mo $(\mathrm{n}=34)$; Methodist Hospital of Indiana, Indianapolis, Ind $(n=20)$; and LDS Hospital, Salt Lake City, Utah $(\mathrm{n}=20)$. The 342 study patients constituted the CryoValve SG pulmonary human heart valve 510(k) clinical study (K033484), funded by CryoLife.

\section{Control Data}

To compare outcomes of patients receiving SGPVs with those of patients receiving conventional valves, similar data from 1246 conventionally processed CryoValve pulmonary valves (1985-2006) used for Ross procedures and RVOT reconstructions were obtained from the CryoLife Clinical Registry (CryoLife, data on file). This registry includes CryoValve data from 7 institutions including 4 (Oklahoma, Denver, Milwaukee, and Salt Lake City) that also participated in this SGPV data collection. The follow-up period for the conventional valve control data was truncated to that available for the SGPV cohort (6.7 years) to aid in comparison.

\section{Preoperative Diagnoses and Operative Procedures}

The overall patient population was divided by operative procedure, Ross procedure or RVOT reconstruction. Within those subgroups, general patient characteristics, preoperative etiology, and previous valve or conduit replacements are shown in Table 1. Included in the RVOT reconstruction subgroup were 81 partial orthotopic procedures, 44 extracardiac procedures, 16 orthotopic reconstructions (all Ross reimplants), and 8 other RVOT reconstructions.

\section{Data Collection Methods}

Patient follow-up data were obtained from hospital and clinic records as well as direct patient contact as necessary. In cases of direct patient followup, the patients were queried regarding their current state of health and asked to provide contact information for their current treating physicians. The treating physicians were then contacted to provide the patients' recent clinical data. All attempts were made to collect recent follow-up, including echocardiographic data from within 1 year of study initiation. Demographic, operative, perioperative, and adverse event data were collected for each patient. Operative and perioperative data included the following: general risk factors, history of cardiac surgery including type of previous valve replacement, operative diagnosis, coexisting cardiac conditions, and concomitant procedures. Adverse events collected included mortality, valve-related mortality, explantation, other cardiac reintervention, endocarditis, thrombosis, thromboembolism, nonstructural dysfunction, and bleeding.

Hemodynamic data (peak or mean transvalvular gradient and valvular insufficiency) from echocardiographic or cardiac catheterization reports were collected preoperatively, at discharge, and as available during the follow-up period. Pulmonary regurgitation was graded semiquantitatively on a 5-point scale as none (0) to severe (4+). All data were collected with uniform case report forms.

\section{Definitions}

Early events were defined as those occurring during the same hospitalization or within 30 days of implantation. All other events were considered late. Valve-related events were documented according to the guidelines for reporting mortality and morbidity after cardiac valve interventions. ${ }^{17}$ Valverelated failure was defined as valve reintervention, valve explantation, or clinical evidence of valve-related mortality.

\section{Valve Processing}

All valves for the study were processed by CryoLife, either with the SynerGraft process ${ }^{18}$ or with the conventional processing methodology for CryoValve (control data). ${ }^{19}$ The SynerGraft process uses hypotonic lysis and nuclease digestion of the cellular elements, along with repeated washing of the tissue. The process removes more than $99 \%$ of the cells and nucleic acids from all elements of the tissue matrix. The valves are subsequently cryopreserved in a manner identical to that used for the conventional CryoValve. In vitro testing has shown the SGPV to be identical to the conventional CryoLife valve in biomechanical characteristics, and histologic staining also shows maintenance of normal valve structural elements without cells. ${ }^{20}$

\section{Statistical Methods}

SPSS version 11.5 for Windows statistical software (SPSS, Inc, Chicago, IIl) was used for all statistical analyses. Continuous data are presented as mean $\pm \mathrm{SD}$ and range and were tested for normality with the Kolmogorov-Smirnov test. Normal data were compared with the Student $t$ test, whereas the Mann-Whitney $U$ test was used for comparisons with nonnormally distributed data. Categoric data are presented as proportions and compared with Fisher's Exact Test. Adverse events, including actuarial survival; freedom from valve-related mortality; valve explantation; reoperation or reintervention; thromboembolism, thrombosis, or bleeding; nonstructural dysfunction; valve-related failure; and endocarditis were analyzed with the Kaplan-Meier method. The survival of a patient started at the time of pulmonary valve operation and ended at the time of death (event) or at the last follow-up (censoring). The analysis of allograft valve survival started at the time of implantation and ended with reoperation (event), last follow-up, or patient death (censoring). The Tyrone-Ware test was used to compare Kaplan-Meier curves between groups (correcting for the differences in follow-up time between the groups). Linearized occurrence rates (LORs) were calculated for adverse events as the total number of observed late ( $>30$ days) events divided by the total patient-years of follow-up.

A propensity score for each patient was calculated to determine the probability of valve replacement with SGPV with separate logistic regressions for the RVOT reconstruction and Ross populations. Variables included in the propensity score regression model were chosen according to differences in preoperative baseline characteristics between the conventional valve and 
TABLE 1. Preoperative demographic data for patients undergoing Ross procedure and reconstruction of right ventricular outflow tract

\begin{tabular}{|c|c|c|c|c|c|c|}
\hline & \multicolumn{3}{|c|}{ Ross } & \multicolumn{3}{|c|}{ RVOT } \\
\hline & SGPV & CV & $P$ value & SGPV & CV & $P$ value \\
\hline No. of patients & 193 & 665 & & 149 & 581 & \\
\hline \multicolumn{7}{|l|}{ Age (y) } \\
\hline Mean \pm SD & $30.7 \pm 6.3$ & $28.3 \pm 16.6$ & .07 & $15.0 \pm 13.2$ & $9.7 \pm 12.0$ & .0001 \\
\hline Median & 32.4 & 28.4 & & 13.4 & 5.2 & \\
\hline Range & $0-63.6$ & $0-72.2$ & & $0-69.6$ & $0-70.7$ & \\
\hline$<18$ y $(\%)$ & 27 & 34 & & 75 & 85 & \\
\hline$<1$ y $(\%)$ & 3 & 2 & & 11 & 18 & \\
\hline Sex (\% male $)$ & 71 & 76 & .13 & 62 & 60 & .51 \\
\hline \multicolumn{7}{|l|}{ Valve diameter $(\mathrm{mm})$} \\
\hline Mean \pm SD & $24.6 \pm 2.7$ & $25.1 \pm 3.0$ & .001 & $21.4 \pm 4.3$ & $21.0 \pm 4.6$ & .31 \\
\hline Range & $10-30$ & $12-30$ & & $9-29$ & $8-31$ & \\
\hline Allograft $z$ score $($ mean \pm SD) & $0.42 \pm 1.2$ & $1.0 \pm 1.2$ & .0001 & $0.9 \pm 1.5$ & $1.9 \pm 1.6$ & .0001 \\
\hline Etiology (no.) & & & .02 & & & .0001 \\
\hline Congenital & $123(64 \%)$ & $324(55.2 \%)$ & & $64(43 \%)$ & $315(64 \%)$ & \\
\hline Acquired & $63(33 \%)$ & $234(39.9 \%)$ & & $83(56 \%)$ & $129(26 \%)$ & \\
\hline Congenital and acquired & 1 & 19 & & 1 & 50 & \\
\hline Unknown & 6 & 78 & & 1 & 87 & \\
\hline Previous valve replacement (no.) & $22(11 \%)$ & $50(7.5 \%)$ & .10 & $75(50 \%)$ & $178(30 \%)$ & .0001 \\
\hline Aortic & 22 & 50 & & 18 & 31 & \\
\hline Mechanical & 6 & 16 & & 0 & 3 & \\
\hline Bioprosthesis & 2 & 7 & & 1 & 1 & \\
\hline Allograft & 8 & 22 & & 2 & 2 & \\
\hline Autograft & NA & NA & & 12 & 17 & \\
\hline Unknown & 6 & 5 & & 3 & 8 & \\
\hline Pulmonary & NA & NA & & 73 & 170 & \\
\hline Bioprosthesis & NA & NA & & 3 & 27 & \\
\hline Allograft & NA & NA & & 46 & 120 & \\
\hline Unknown & NA & NA & & 24 & 23 & \\
\hline
\end{tabular}

RVOT, Right ventricular outflow tract reconstruction; $S G P V$, CryoValve SG pulmonary valve; $C V$, CryoValve pulmonary valve; $N A$, not applicable

SGPV groups and included patient age, patient sex, previous valve replacement, congenital etiology, and allograft $z$ score (as determined by comparing the allograft valve diameter and the predicted diameter according to the patient's body surface area). ${ }^{21}$ The propensity score was then forced as a covariable into a Cox proportional hazards model for late mortality and late valve-related failure to correct for treatment assignment.

\section{RESULTS}

\section{Follow-up}

Among the 342 SGPV recipients identified, follow-up was complete ${ }^{22}$ (defined as follow-up after January 1, 2006 , or known adverse event) for $99 \%$. This represents a mean follow-up of 4.0 years (range, $0-6.7$ ), equating to 1350 patient-years, with 855 and 495 patient-years for Ross and RVOT reconstruction groups, respectively. The conventional valve control data follow-up was $94 \%$ complete, representing a mean follow-up of 3.7 years (range, 0-6.7 patient-years), equating to 4653 patient years, with 2681 and 1954 patient-years for Ross and RVOT reconstruction groups, respectively.

\section{Survival}

In the SGPV Ross group, there were 3 early deaths $(1.6 \%$, 2 pediatric, 1 adult); none were valve related. There were
4 late deaths (all adult), with 1 late death (sudden unexplained death) at postoperative day 51, possibly valve related because an echocardiographic examination the previous week had shown pulmonic stenosis along with moderate to severe tricuspid regurgitation (Table 2). Early deaths occurred in 26 conventional valve Ross cases $(3.9 \%, 11$ pediatric, 15 adult); 3 were valve related. An additional 7 conventional valve Ross late deaths (3 pediatric, 4 adult) occurred, none of which were valve related. Comparing the SGPV subpopulation with the conventional valve subpopulation, 5-year actuarial survivals (Table 3 and Figure 1) were similar for the SGPV $(96.9 \% \pm 1.3 \%)$ and conventional valve $(94.8 \% \pm 0.9 \%)$ Ross subpopulations.

There were 4 early deaths among the SGPV recipients undergoing RVOT reconstruction $(2.7 \%, 1$ pediatric, 3 adults); no early deaths were valve related. Late deaths occurred in 6 SGPV recipients undergoing RVOT reconstruction (4 pediatric, 2 adult); 3 late deaths (sudden unexplained deaths) were possibly valve related; however, there was no clinical evidence to suggest failure of the implanted valve (Table 2). Among the conventional valve recipients undergoing RVOT reconstruction, there were 49 early deaths $(8.4 \%$, 45 pediatric, 4 adult); 1 was valve related. There were 31 
TABLE 2. Reported causes of late mortality for the CryoValve SG pulmonary valve population

\begin{tabular}{lccccc}
\hline Procedure & Time from implant (d) & Age at implant (y) & Previous valve surgery & Description of event & Valve related \\
\hline Ross & 153 & 45 & No & Fungal mediastinitis, tore hole in aortic graft \\
Ross & 577 & 35 & No & Myocardial infarction from coronary artery disease & No \\
Ross & 51 & 47 & No & Sudden unexplained death \\
Ross & 1900 & 27 & No & Cancer & Yes \\
RVOT & 1265 & 1 & No & Arrhythmia complications after pacemaker implant & No \\
RVOT & 389 & 51 & Pulmonary valvotomy & Sudden unexplained death & Yes \\
RVOT & 339 & 11 & 2 valve replacements & Sudden unexplained death \\
RVOT & 149 & 0.6 & No & Severe tracheal bronchomalacia \\
RVOT & 113 & 29 & Pulmonary valvotomy & Sudden unexplained death \\
RVOT & 338 & 5.2 & Cardiac surgery & Arrhythmia-related death \\
\hline
\end{tabular}

RVOT, Right ventricular outflow tract reconstruction.

late deaths among conventional valve recipients undergoing RVOT reconstruction ( 26 pediatric, 5 adult), of which 6 were valve related. Overall survival after RVOT reconstruction was apparently improved $(P<.01)$ in the SGPV recipients $(92.3 \% \pm 2.4 \%)$ relative to the conventional valve recipients $(84.6 \% \pm 1.6 \%)$, primarily because of an increase in early mortality after conventional valve RVOT reconstructions because late mortality LORs were comparable. This observation probably reflects the earlier era of surgery in the conventional valve cohort.

The likelihood of receiving SGPV for each patient was determined (see Table 4 for covariables used in the model to develop the propensity scores) and forced into the Cox proportional hazards model for late mortality. Type of valve replacement (SGPV or conventional valve) was not a significant predictor for mortality in the propensity-adjusted Cox proportional hazards model for patients undergoing RVOT reconstruction $(P=.29$; hazard ratio $[\mathrm{HR}], 0.73 ; 95 \%$ confidence interval, $[\mathrm{CI}] 0.3-1.8)$. Additionally, the propensity score was not significant for the Cox proportional hazards model for the RVOT reconstruction population $(P=.47$; HR, $0.34 ; 95 \%$ CI, 0.01-6.5). Because there were only 11 late deaths in the Ross cohort, propensity score-adjusted comparison of late mortality was not attempted.

\section{Adverse Events}

The LOR for late adverse events shows a low risk of event occurrence with time for most events, with valve-related failure being the most commonly occurring complication (varying from $0.93 \%$ per patient-year among conventional valve recipients undergoing the Ross procedure to $2.71 \%$ per patient-year among conventional valve recipients undergoing RVOT reconstruction). There were no differences in event occurrence between SGPVs and conventional valves for both Ross and RVOT reconstruction populations. Valve-related complications during follow-up, summarized by actuarial freedom from events at 5 years and LOR for late events, are included in Table 3. Figure 1 shows the Kaplan-Meier actuarial freedoms from mortality, valve explantation, and valve-related failure in Ross and RVOT reconstruction populations receiving SGPVs or conventional valve allografts.

\section{Valve-Related Failure}

Thirteen instances of late valve-related failure occurred in 11 SGPV recipients undergoing the Ross operation (2 pediatric). The predominant mode of failure was valvular stenosis or conduit obstruction (12 events). Intervention was accomplished in 6 instances with balloon treatment and by stent placement in 1 . The valve was explanted in 5 instances,

TABLE 3. Actuarial freedoms from adverse events at 5 years and linearized occurrence rates for patients undergoing Ross procedure and right ventricular outflow tract reconstruction with CryoValve SG and CryoValve pulmonary valves

\begin{tabular}{|c|c|c|c|c|c|c|c|c|}
\hline \multirow[b]{4}{*}{ Event } & \multicolumn{4}{|c|}{ Ross } & \multicolumn{4}{|c|}{ RVOT } \\
\hline & \multirow{2}{*}{\multicolumn{2}{|c|}{$\begin{array}{c}5-y \text { freedom } \\
\text { from event }(\% \pm \mathrm{SE})\end{array}$}} & \multirow{2}{*}{\multicolumn{2}{|c|}{$\operatorname{LOR}(\% / \mathbf{y})$}} & \multirow{2}{*}{\multicolumn{2}{|c|}{$\begin{array}{c}5-y \text { freedom } \\
m \text { event }(\% \pm S E)\end{array}$}} & \multirow{2}{*}{\multicolumn{2}{|c|}{$\operatorname{LOR}(\% / y)$}} \\
\hline & & & & & & & & \\
\hline & SGPV & $\mathrm{CV}$ & SGPV & $\mathrm{CV}$ & SGPV & $\mathrm{CV}$ & SGPV & $\mathrm{CV}$ \\
\hline Mortality & $96.9 \% \pm 1.3 \%$ & $94.8 \% \pm 0.9 \%$ & $0.47 \%$ & $0.26 \%$ & $92.3 \% \pm 2.4 \% *$ & $84.6 \% \pm 1.6 \% *$ & $1.21 \%$ & $1.59 \%$ \\
\hline Valve-related failure & $93.9 \% \pm 1.8 \%$ & $96.3 \% \pm 0.8 \%$ & $1.50 \%$ & $0.93 \%$ & $93.4 \% \pm 2.3 \%$ & $89.3 \% \pm 1.6 \%$ & $1.61 \%$ & $2.71 \%$ \\
\hline Endocarditis & $100 \% \pm 0.0 \%$ & $99.3 \% \pm 0.4 \%$ & $0.00 \%$ & $0.15 \%$ & $98.3 \% \pm 1.2 \%$ & $99.4 \% \pm 0.4 \%$ & $0.20 \%$ & $0.1 \%$ \\
\hline $\begin{array}{l}\text { Thromboembolism, valve } \\
\text { thrombosis, bleeding }\end{array}$ & $98.9 \% \pm 0.8 \%$ & $97.1 \% \pm 0.7 \%$ & $0.12 \%$ & $0.11 \%$ & $99.3 \% \pm 0.7 \%$ & $98.0 \% \pm 0.6 \%$ & $0.20 \%$ & $0.05 \%$ \\
\hline Explantation & $97.0 \% \pm 1.4 \%$ & $96.4 \% \pm 0.9 \%$ & $0.46 \%$ & $0.90 \%$ & $97.6 \% \pm 1.3 \% \dagger$ & $91.4 \% \pm 0.7 \% \dagger$ & $0.81 \%$ & $2.15 \%$ \\
\hline Reintervention & $94.4 \% \pm 1.7 \%$ & $95.5 \% \pm 0.9 \%$ & $1.3 \%$ & $0.93 \%$ & $92.7 \% \pm 2.4 \%$ & $89.5 \% \pm 1.6 \%$ & $1.62 \%$ & $2.71 \%$ \\
\hline Valve-related death & $99.5 \% \pm 0.5 \%$ & $99.5 \% \pm 0.3 \%$ & $0.17 \%$ & $0 \%$ & $97.8 \% \pm 1.3 \%$ & $98.2 \% \pm 0.7 \%$ & $0.60 \%$ & $0.26 \%$ \\
\hline Nonstructural valve dysfunction & $100 \% \pm 0.0 \%$ & $99.9 \% \pm 0.2 \%$ & $0 \%$ & $0 \%$ & $100 \% \pm 0.0 \%$ & $99.6 \% \pm 0.3 \%$ & $0 \%$ & $0 \%$ \\
\hline
\end{tabular}

RVOT, Right ventricular outflow tract; $L O R$, linearized occurrence rate; $S G P V$, CryoValve SG pulmonary valve; $C V$, CryoValve pulmonary valve. $* P=.009 . \dagger P=.07$. 
2 of which followed a previous balloon treatment, and there was 1 valve-related death with clinical evidence of pulmonic stenosis. Twenty-five instances of late valve-related failure occurred in 22 conventional valve recipients undergoing Ross procedures, with 1 patient having a second occurrence after intervention and 1 patient having 3 interventions. The predominant cause of failure was also stenosis or conduit obstruction (21 events). There was 1 instance of insufficiency alone and 2 of mixed stenosis and insufficiency. Calcification of the valve (in most cases also associated with stenosis) was observed in 6 instances; there were 3 instances of leaflet degeneration noted at explantation. Freedoms from valve-related failure at 5 years for the Ross population were $93.9 \%$ $\pm 1.8 \%$ in the SGPV subpopulation and $96.3 \% \pm 0.8 \%$ in the conventional valve subpopulation (Table 3 and Figure 1).

In the SGPV RVOT reconstruction subgroup, late valverelated failure occurred in 8 instances (all but 1 pediatric). The predominant cause of failure was stenosis of the valve or distal pulmonary arteries (5 cases). Intervention was accomplished in 3 cases with balloon treatment and stenting of the pulmonary branch arteries in 1 patient. To date, none of these RVOT reinterventions have proceeded to explantation. There were also 4 valve explantations, 3 for severe insufficiency and 1 for stenosis. Two heart transplants occurred during follow-up in the RVOT reconstruction group; however, these cases were not included as valve-related failures because the need for a heart transplant was not attributed to the pulmonary valve and at the time of heart transplant no evidence of pulmonary valve-related failure was observed. In the conventional valve RVOT reconstruction subpopulation, 53 cases of valve-related failure occurred in 48 patients, with 3 patients having a second occurrence after intervention and 1 patient having 3 interventions. For the conventional valve RVOT reconstruction subpopulation, the predominant cause of failure was also stenosis (19 cases), but insufficiency was also common (15 cases) and in 8 cases patients had mixed stenoses and insufficiency. Calcification of the valve (in most cases also associated with stenosis) was observed in 15 instances; there were 6 instances of leaflet degeneration noted at explantation, 1 pseudoaneurysm, 2 other events, and 7 cases in which failure mode was not provided. Freedoms from valve-related failure at 5 years for the RVOT reconstruction population was $93.4 \% \pm 2.3 \%$ in the SGPV subpopulation and $89.3 \% \pm 1.6 \%$ in the conventional valve subpopulation (Table 3 and Figure 1).

The propensity score for receiving SGPV was forced into the Cox proportional hazards model for valve-related failure separately for Ross and RVOT reconstruction populations. Type of valve replacement (SGPV or conventional valve) was not a significant predictor for late valve-related failure in the propensity-adjusted Cox proportional hazards model for the Ross population $(P=.25$; HR, 1.6 ; $95 \% \mathrm{CI}$; $0.7-$
$3.5)$ or the RVOT reconstruction population $(P=.27$; HR, $0.64 ; 95 \%$ CI, $0.3-1.4$ ). Additionally, the propensity score was not significant for either the Ross population $(P=$ .53 ; HR, 2.5; 95\% CI, 0.1-44.6) or the RVOT reconstruction population $(P=.75 ; \mathrm{HR}, 0.75 ; 95 \% \mathrm{CI}, 0.2-14.5)$ in the Cox proportional hazards model.

\section{Other Events}

One case of endocarditis was reported among the SGPV recipients, that of a patient at day 1044 after RVOT reconstruction. Late thromboembolic or bleeding events occurred in 2 SGPV recipients: 1 patient displayed 2 echo dense masses on the allograft at day 124 after the Ross operation, which resolved following anticoagulation, and 1 patient had pulmonary embolism as a consequence of RVOT aneurysm at day 1736 after RVOT reconstruction (this patient was awaiting surgery at last follow-up). Nonstructural valve dysfunction was not observed among the SGPV recipients. Among the conventional valve recipients, there were 3 instances of nonstructural valve dysfunction, all of which were suture-line dehiscences occurring early after implantation.

\section{Hemodynamic Function}

Echocardiographic data at last follow-up were available from 162 SGPV patients undergoing the Ross procedure ( $90 \%$ of population still at risk) at a mean follow-up of 3.9 years (range, 1-6.6 years) and 115 SGPV recipients undergoing RVOT reconstruction (87\% of population still at risk) at a mean follow-up of 3.2 years (range, 1-6.4 years). Peak gradients and pulmonary insufficiency grades were compared with data available from 368 conventional valve recipients undergoing the Ross procedure (61\% of population still at risk) at a mean follow-up of 3.7 years (range, $1-6.2$ years) and 188 conventional valve recipients undergoing RVOT reconstruction ( $41 \%$ of population still at risk) at a mean follow-up of 3.6 years (range, 1-6.0 years).

The mean peak pulmonary gradient was $19.0 \pm 17.2 \mathrm{~mm}$ $\mathrm{Hg}$ for $151 \mathrm{SGPV}$ recipients undergoing the Ross procedure versus $21.7 \pm 16.7 \mathrm{~mm} \mathrm{Hg}$ for 323 conventional valve recipients $(P<.002$; Figure 2$)$. In the RVOT reconstruction population, however, mean peak gradient did not differ between 110 SGPV recipients $(22.9 \pm 17.4 \mathrm{~mm} \mathrm{Hg})$ and 168 conventional valve recipients $(22.2 \pm 15.3 \mathrm{~mm} \mathrm{Hg}$; Figure 2$)$. Additionally, pulmonary insufficiency grades were significantly lower in SGPV recipients relative to conventional valve recipients undergoing both Ross procedures $(P<.01)$ and RVOT reconstruction $(P<.01$; Figure 3$)$.

\section{DISCUSSION}

The SGPV provides patients undergoing Ross procedures and RVOT reconstruction with a functional and durable solution at 4-year follow-up, with low occurrence rates of endocarditis and other valve-related complications. Valve type 


\section{Actuarial Freedom from Mortality, Explant and Valve-Related Failure}
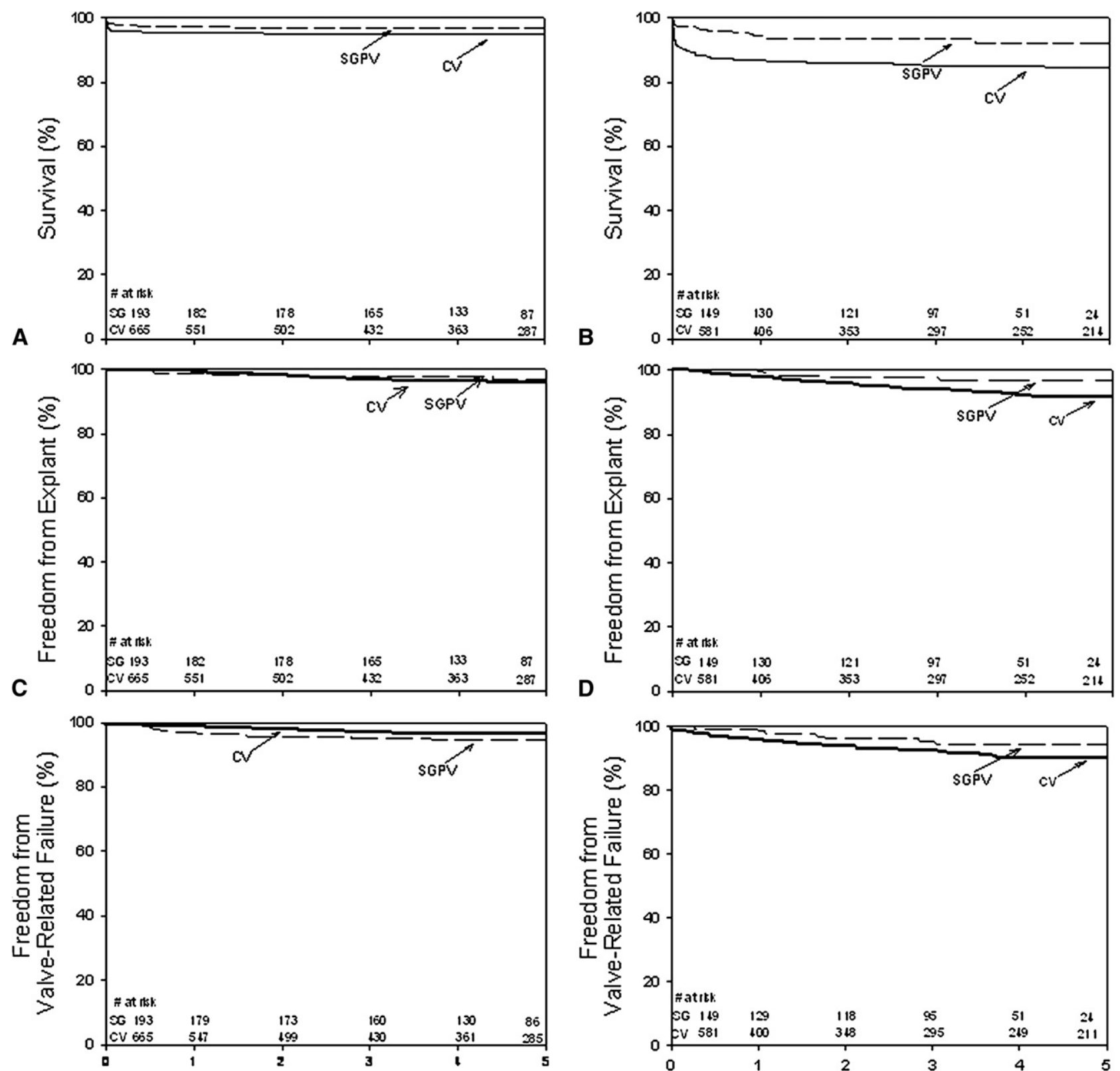

E

Time (years)

$\mathbf{F}$

Time (years)

\begin{tabular}{ccccccc|ccccccc}
\hline $\begin{array}{c}\text { \% } \\
\text { Freedom }\end{array}$ & Mortality & \multicolumn{4}{c}{$\begin{array}{c}\text { Ross } \\
\text { Explant }\end{array}$} & $\begin{array}{c}\text { Valve-Related } \\
\text { Failure }\end{array}$ & Mortality & & \multicolumn{4}{c}{ RVOT } \\
Explant & \multicolumn{4}{c}{$\begin{array}{c}\text { Valve-Related } \\
\text { Failure }\end{array}$} \\
Years & SGPV & CV & SGPV & CV & SGPV & CV & SGPV & CV & SGPV & CV & SGPV & CV \\
1 & 97.4 & 95.6 & 98.9 & 99.3 & 96.8 & 98.9 & 94.4 & 86.7 & 100 & 98.0 & 99.3 & 95.8 \\
3 & 96.9 & 95.0 & 97.8 & 96.7 & 95.1 & 96.9 & 93.6 & 85.3 & 97.7 & 93.9 & 95.2 & 92.3 \\
5 & 96.9 & 94.8 & 97.0 & 95.9 & 94.4 & 96.4 & 92.3 & 84.6 & 96.6 & 91.4 & 94.2 & 89.9
\end{tabular}


(SGPV or conventional valve) was not a significant predictor for valve-related failure in the propensity-adjusted analysis. Five-year freedoms from valve-related failure were not significantly different when comparing the SGPV with the conventionally processed valve. Echocardiographic parameters, however, suggest that valve performance after 4 years was improved with SGPV. Peak gradients in the Ross SGPV subpopulation were statistically lower, although it remains to be determined whether this statistical improvement is clinically relevant. Improvement in valve competence after both Ross procedure and RVOT reconstruction was observed among SGPV recipients relative to conventional valve recipients.

\section{Historical Reports of Allograft Durability}

In the 1960s and mid 1970s, the use of allografts for aortic and pulmonary valve replacement was hypothesized to be associated with superior durability relative to second-generation bioprostheses. With time, the various methods for allograft valve processing were observed to have divergent outcomes, with poor results observed when most sterilization methods were used (irradiation, ethylene oxide treatment, long-term maintenance in antibiotics); however, long-term outcomes with fresh and cryopreserved valves were observed to be superior. ${ }^{4,23}$ It was speculated that maintenance of viability was therefore important in the long-term function of allograft valves. In the last 2 decades, allograft processing around the world has primarily been accomplished by cryopreservation to maintain a degree of graft viability and allow for long periods of storage. Structural failure has continued to be an issue with allografts, however, leading to much speculation that failure may be partly related to the persistence of cellularity and the resulting immunogenicity of the grafts. ${ }^{8-11,24}$

The 94\% 5-year freedom from valve-related failure in the Ross SGPV subpopulation is comparable to literature reports of $92 \%$ to $96 \%$ at 5 to 7 years after the Ross operation among patients with conventionally processed allografts. ${ }^{1,3,6,25}$

Freedom from valve-related failure with conventionally processed allograft valves in RVOT reconstruction has been reported as $60 \%$ to $74 \%$ at 5 years. ${ }^{7,26}$ Patients in these published series were primarily younger (mean ages of 3.6 and 4.3 years) than in this series. Another series reporting on 297 patients undergoing RVOT reconstruction with mean age of 18 years showed freedom from valve-related events of $80 \%$ at 8 years. $^{27}$ Our current results with $93 \%$ freedom from valve-related failure at 5 years among
SGPV recipients are encouraging; the older mean age of the SGPV recipients ( 15 years) could be a factor contributing to these positive results, but $50 \%$ of patients in this RVOT reconstruction series had received the SGPV after a previous failed graft and thus could also be argued to present a more difficult challenge.

The SynerGraft process has been shown to provide effective reduction in antigenic donor cells and cell remnants. ${ }^{20,28}$ Maintenance of the structural integrity of the resulting decellularized matrix was previously only surmised from available in vitro data and relatively short-term if promising clinical data. $^{13-16,20,29,30}$ This study provides additional evidence, with implantation time now approaching 7 years, that this process effectively maintains structural integrity of the valve, with possible improvements in hemodynamic performance. An extended follow-up of the SGPV group will help determine whether the reduced immunogenicity and improved hemodynamics will lead to superior longer-term durability.

\section{Other Valve-Related Complications}

Allograft endocarditis was uncommon among the SGPV recipients, with only 1 case among those undergoing RVOT reconstruction. This underlines the resistance of the SGPV to infection and is comparable to other reports. ${ }^{1,2,4}$ ${ }^{6,27}$ Furthermore, the absence of nonstructural valve-related failure and extremely low occurrence rates of thromboembolic and bleeding complications illustrate the benefits that the SGPV has in common with the conventional valve. ${ }^{1,4,6,27}$

\section{Comparison with Conventional Valve}

We compared outcomes after SGPV implantation with those of a historical cohort of patients who received conventional pulmonary valves to assess whether the SynerGraft treatment had any effect on valve performance. Although there were differences between the 2 populations with regard to both patient characteristics and era of operation (primarily in the RVOT reconstruction groups) late survival was comparable for the Ross and the RVOT reconstruction populations. Importantly, the propensity-adjusted late survival was equivalent for conventional and SGPV recipients undergoing RVOT reconstruction. Freedom from explantation was also comparable for the SGPV and conventional valve recipients undergoing the Ross procedure; however, SGPV tended to reduce explantation rate in the RVOT reconstruction population, possibly because of the differences in patient age and disease etiology. Of note, the incidence of

FIGURE 1. Actuarial freedoms from mortality, valve explantation, and valve-related failure. Actuarial freedoms from mortality (A and B), valve explantation $(\mathrm{C}$ and $\mathrm{D})$, and valve-related failure (E and $\mathrm{F})$ for patients undergoing Ross procedure (A, C, and $\mathrm{E})$ and right ventricular outflow tract $(R V O T)$ reconstruction $(\mathrm{B}, \mathrm{D}$, and $\mathrm{F}$ ) with CryoValve SG pulmonary valves $(S G P V)$ or conventionally processed CryoValve pulmonary valves $(C V)$. Number of patients at risk is provided yearly. 
TABLE 4. Predictors of selection for CryoValve SG pulmonary valve

\begin{tabular}{|c|c|c|c|c|c|c|}
\hline \multirow[b]{2}{*}{ Predictor } & \multicolumn{3}{|c|}{ Ross } & \multicolumn{3}{|c|}{ RVOT } \\
\hline & OR & $\mathbf{9 5} \% \mathrm{CI}$ & $P$ value & OR & $95 \%$ CI & $P$ value \\
\hline Previous aortic or pulmonary valve replacement & 2.4 & $1.3-4.4$ & .004 & 2.1 & $1.4-3.1$ & .001 \\
\hline Age & 1.0 & $0.9-1.0$ & .940 & 1.0 & $0.9-1.0$ & .299 \\
\hline Female sex & 1.8 & $1.2-2.6$ & .004 & 1.1 & $0.7-1.6$ & .688 \\
\hline Allograft $z$ score & 0.6 & $0.5-0.7$ & .0001 & 0.6 & $0.5-0.7$ & .621 \\
\hline Congenital etiology & 2.5 & $1.7-3.6$ & .0001 & 1.0 & $0.7-1.5$ & .958 \\
\hline
\end{tabular}

RVOT, Right ventricular outflow tract reconstruction; $O R$, odds ratio; $C I$, confidence interval.

valve calcification appears to be reduced among the SGPV recipients. At explantation, only 1 SGPV was reported as calcified $(11 \%$ of the valve-related explantations, $0.3 \%$ of the total population), compared with 21 cases among the conventional valve recipients ( $35 \%$ of the total valve-related explantations, $1.6 \%$ of the total population).

Valve function, as assessed by peak pulmonary gradients and insufficiency, was improved at last follow-up with the SGPV relative to the conventional valve. SGPV recipients undergoing Ross procedures showed lower peak gradients and improved competence at similar follow-up when compared with conventional valve recipients. There was no difference in peak gradients for the RVOT reconstruction cohort, but SGPV recipients did demonstrate improved valve competence, although the older age of the SGPV population could be a factor in this result. Although the 4-year hemodynamic performance in the SGPV recipients may

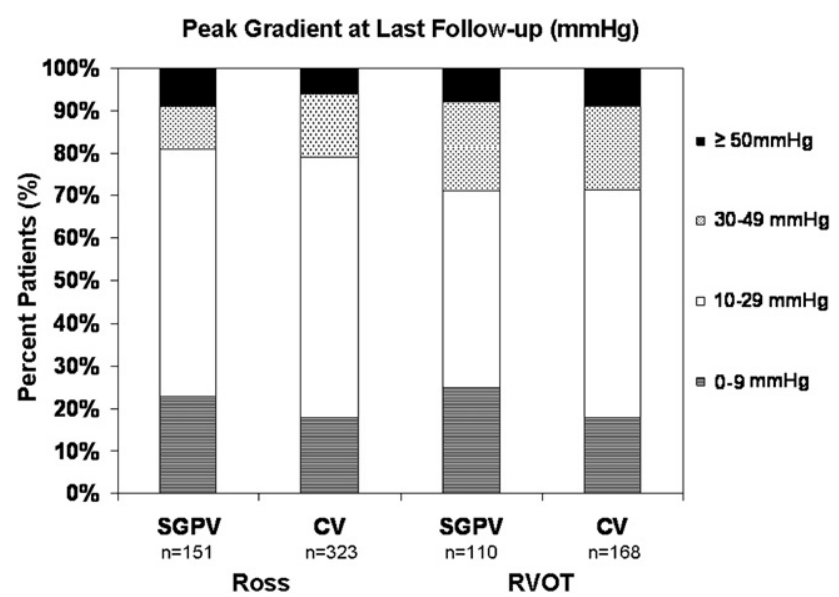

FIGURE 2. Peak gradient at last follow-up. Proportion of patients undergoing Ross procedure or right ventricular outflow tract (RVOT) reconstruction with CryoValve SG pulmonary valve ( $S G P V)$ or conventionally processed CryoValve $(\mathrm{CV})$ with peak pulmonary gradients 0 to 9,10 to 29,30 to 49 or at least $50 \mathrm{~mm} \mathrm{Hg}$. Peak pulmonary gradient was measured at mean follow-up of $3.9 \pm 1.4$ years for CryoValve SG pulmonary valves in Ross procedure, $4.1 \pm 1.5$ years for conventional CryoValves in Ross procedure, $3.3 \pm 1.4$ years for CryoValve SG pulmonary valves in right ventricular outflow tract reconstruction, and $3.7 \pm 1.4$ years for conventional CryoValves in right ventricular outflow tract reconstruction. Number of patients with peak gradient measured is shown below each bar. have been improved, the propensity-adjusted analysis for valve-related failure did not identify valve type as a risk factor for failure for patients undergoing either the Ross procedure or RVOT reconstruction.

This report is consistent with short-term data reported on the SGPV by several centers. Tavakkol and colleagues ${ }^{29}$ compared 26 SGPV recipients with 26 historical agematched recipients of conventionally processed valves. The mean age of the SGPV group was 61 months. At a mean follow-up of 19 months, the SGPV group showed significantly less regurgitation than the conventional valve group. Although the mean peak gradient was low in both groups, it was statistically lower in the SGPV group $(7.6 \mathrm{~mm}$ $\mathrm{Hg}$ vs $14.6 \mathrm{~mm} \mathrm{Hg}$ ). Hawkins and colleagues ${ }^{16}$ also reported echocardiographic follow-up at a mean of 8 months for 8 SGPV valves versus 8 conventionally processed valves for RVOT reconstruction. The average peak gradient for the SGPV was $13 \mathrm{~mm} \mathrm{Hg}$, as compared with $24 \mathrm{~mm} \mathrm{Hg}$ for the conventional valve.

Bechtel, Stierle, and Sievers ${ }^{31}$ have recently published their Ross series with SGPVs and compared these grafts with conventional pulmonary allografts. At a mean of 52 months (maximum 71 months), they have had no reoperations in their SGPV recipients and state that this provides evidence for durability of the SGPV. Mean peak gradients were slightly but statistically higher in their SGPV recipients than among their control patients, but the increase occurred primarily within the first 6 months of implantation and has been stable since. There was no pulmonary insufficiency observed in this series of SGPV recipients undergoing the Ross procedure, supporting our observation of reduced pulmonary insufficiency with the SGPV.

\section{LIMITATIONS}

SGPV valve performance was compared with a historical retrospective conventional valve cohort. Differences in era of implantation could have influenced the results of the study, because the conventional valve cohort was from an earlier era than the SGPV cohort. This factor could not be addressed by the multivariate analysis, because the eras of implantation did not have sufficient overlap, so this difference is still an outstanding limitation of the study. There were significant differences in patient ages between the 


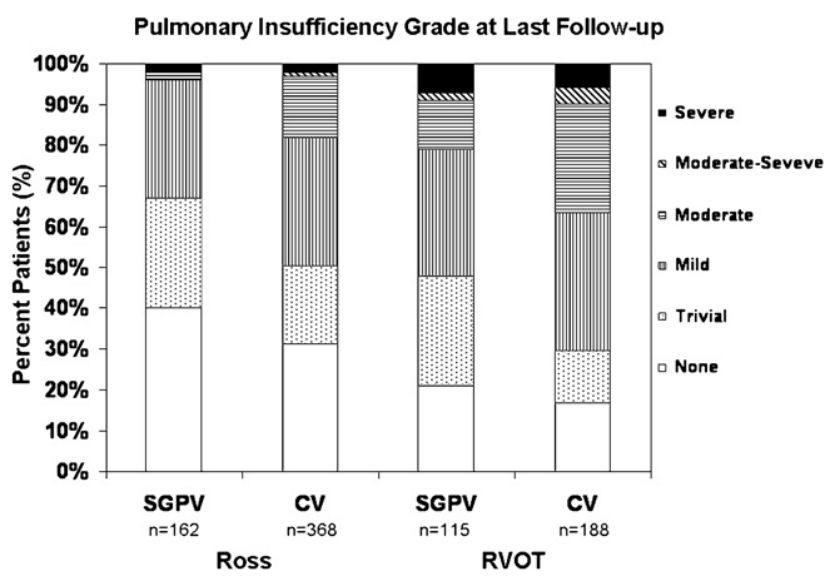

FIGURE 3. Pulmonary insufficiency grade at last follow-up. Pulmonary insufficiency grades of patients undergoing Ross procedure or right ventricular outflow tract (RVOT) reconstruction with CryoValve SG pulmonary valves $(S G P V)$ or conventionally processed CryoValves $(C V)$. Pulmonary insufficiency grade was measured at mean follow-up of $4.1 \pm 1.4$ years for CryoValve SG pulmonary valves in Ross procedure, $3.7 \pm 1.5$ years for conventional CryoValves in Ross procedure, $3.3 \pm 1.3$ years for CryoValve SG pulmonary valves in right ventricular outflow tract reconstruction, and $3.7 \pm 1.5$ years for conventional CryoValves in right ventricular outflow tract reconstruction. Number of patients with pulmonary insufficiency grade measured is shown below each bar.

two RVOT reconstruction subpopulations, with the SGPV recipients being older than the conventional valve recipients. The propensity-adjusted model for valve-related failure and survival did not, however, indicate a difference in valve type while accounting for the difference in age. Because this was a purely retrospective study, the cardiologic evaluations by the patient physicians were accepted, and there was no standard protocol for reporting echocardiographic data. Longer follow-up is needed to determine whether the reduced alloantibody response of the SGPV valve and improvements in hemodynamic performance persist and whether they will translate into increased valve durability.

\section{CONCLUSIONS}

This multicenter, retrospective cohort study of 342 consecutive patients receiving the SGPV supports earlier evidence that the SGPV is an appropriate graft for patients requiring pulmonary valve replacement or reconstruction. Overall, at a mean of 4 years the SGPV appears to be safe and have at least comparable, if not improved, hemodynamic performance. A compelling reason for use of the SynerGraft-processed valve is the possibility that reduced cellular content provides an immunologic benefit to the patient. Whether this benefit translates to greater valve longevity or better long-term function remains to be demonstrated. Additional long-term follow-up of these patients is ongoing and may answer some of the remaining questions regarding potential clinical benefits of the SGPV.

\section{References}

1. Kouchoukos NT, Masetti P, Nickerson NJ, Castner CF, Shannon WD, DavilaRoman VG. The Ross procedure: long-term clinical and echocardiographic follow-up. Ann Thorac Surg. 2004;78:773-81.

2. Dearani JA, Orszulak TA, Schaff HV, Daly RC, Anderson BJ, Danielson GK. Results of allograft aortic valve replacement for complex endocarditis. $J$ Thorac Cardiovasc Surg. 1997;113:285-91.

3. Niwaya K, Knott-Craig CJ, Lane MM, Chandrasekaren K, Overholt ED, Elkins RC. Cryopreserved homograft valves in the pulmonary position: risk analysis for intermediate-term failure. J Thorac Cardiovasc Surg. 1999;117: 141-6.

4. O'Brien MF, Harrocks S, Stafford EG, Gardner MA, Pohlner PG, Tesar PJ, et al. The homograft aortic valve: a 29 -year, $99.3 \%$ follow up of 1,022 valve replacements. J Heart Valve Dis. 2001;10:334-44.

5. Oswalt JD, Dewan SJ, Mueller MC, Nelson S. Highlights of a ten-year experience with the Ross procedure. Ann Thorac Surg. 2001;71(5 Suppl):S332-5.

6. Takkenberg JJ, Dossche KM, Hazekamp MG, Nijveld A, Jansen EW, Waterbolk TW, et al. Report of the Dutch experience with the Ross procedure in 343 patients. Eur J Cardiothorac Surg. 2002;22:70-7.

7. Tweddell JS, Pelech AN, Frommelt PC, Mussatto KA, Wyman JD, Fedderly RT, et al. Factors affecting longevity of homograft valves used in right ventricular outflow tract reconstruction for congenital heart disease. Circulation. 2000;102 (19 Suppl. 3):III130-5.

8. Baskett RJ, Ross DB, Nanton MA, Murphy DA. Factors in the early failure of cryopreserved homograft pulmonary valves in children: preserved immunogenicity? J Thorac Cardiovasc Surg. 1996;112:1170-8.

9. Dignan R, O’Brien M, Hogan P, Thornton A, Fowler K, Byrne D, et al. Aortic valve allograft structural deterioration is associated with a subset of antibodies to human leukocyte antigens. J Heart Valve Dis. 2003;12:382-90.

10. Hawkins JA, Breinholt JP, Lambert LM, Fuller TC, Profaizer T, McGough EC, et al. Class I and class II anti-HLA antibodies after implantation of cryopreserved allograft material in pediatric patients. J Thorac Cardiovasc Surg. 2000;119: 324-30.

11. Smith JD, Hornick PI, Rasmi N, Rose ML, Yacoub MH. Effect of HLA mismatching and antibody status on "homovital" aortic valve homograft performance. Ann Thorac Surg. 1998;66(6 Suppl):S212-5.

12. Clarke DR, Campbell DN, Hayward AR, Bishop DA. Degeneration of aortic valve allografts in young recipients. J Thorac Cardiovasc Surg. 1993;105:934-41.

13. Bechtel JF, Muller-Steinhardt M, Schmidtke C, Brunswik A, Stierle U, Sievers HH. Evaluation of the decellularized pulmonary valve homograft (SynerGraft). J Heart Valve Dis. 2003;12:734-9.

14. Zehr KJ, Yagubyan M, Connolly HM, Nelson SM, Schaff HV. Aortic root replacement with a novel decellularized cryopreserved aortic homograft: postoperative immunoreactivity and early results. J Thorac Cardiovasc Surg. 2005;130: 1010-5.

15. Elkins RC, Lane MM, Capps SB, McCue C, Dawson PE. Humoral immune response to allograft valve tissue pretreated with an antigen reduction process. Semin Thorac Cardiovasc Surg. 2001;13(4 Suppl. 1):82-6.

16. Hawkins JA, Hillman ND, Lambert LM, Jones J, Di Russo GB, Profaizer T, et al Immunogenicity of decellularized cryopreserved allografts in pediatric cardiac surgery: comparison with standard cryopreserved allografts. J Thorac Cardiovasc Surg. 2003;126:247-52.

17. Akins CW, Miller DC, Turina MI, Kouchoukos NT, Blackstone EH, Grunkemeier GL, et al. Guidelines for reporting mortality and morbidity after cardiac valve interventions. J Thorac Cardiovasc Surg. 2008;135:732-8.

18. Goldstein S, Black KS, inventors; CryoLife, Inc., assignee. Tissue decellularization. United States patent US 7318998. 2008 Jan 15.

19. McNally RT, Heacox A, Brockbank KG, Bank HL, inventors; CryoLife, Inc., assignee. Method for cryopreserving heart valves. United States patent US 4890457. 1990 Jan 2.

20. Elkins RC, Dawson PE, Goldstein S, Walsh SP, Black KS. Decellularized human valve allografts. Ann Thorac Surg. 2001;71(5 Suppl):S428-32.

21. Capps SB, Elkins RC, Fronk DM. Body surface area as a predictor of aortic and pulmonary valve diameter. J Thorac Cardiovasc Surg. 2000;119:975-82.

22. Clark TG, Altman DG, De Stavola BL. Quantification of the completeness of follow-up. Lancet. 2002;359:1309-10.

23. Yap CH, Yii M. Allograft aortic valve replacement in the adult: a review. Heart Lung Circ. 2004;13:41-51.

24. Smith JD, Ogino H, Hunt D, Laylor RM, Rose ML, Yacoub MH. Humoral immune response to human aortic valve homografts. Ann Thorac Surg. 1995; 60(2 Suppl):S127-30. 
25. Forbess JM, Shah AS, St Louis JD, Jaggers JJ, Ungerleider RM. Cryopreserved homografts in the pulmonary position: determinants of durability. Ann Thorac Surg. 2001;71:54-9.

26. Brown JW, Ruzmetov M, Rodefeld MD, Vijay P, Turrentine MW. Right ventricular outflow tract reconstruction with an allograft conduit in non-Ross patients: risk factors for allograft dysfunction and failure. Ann Thorac Surg. 2005;80: 655-63.

27. Gerestein CG, Takkenberg JJ, Oei FB, Cromme-Dijkhuis AH, Spitaels SE, van Herwerden LA, et al. Right ventricular outflow tract reconstruction with an allograft conduit. Ann Thorac Surg. 2001;71:911-7.

28. O'Brien MF, Goldstein S, Walsh S, Black KS, Elkins R, Clarke D. The SynerGraft valve: a new acellular (nonglutaraldehyde-fixed) tissue heart valve for autologous recellularization first experimental studies before clinical implantation. Semin Thorac Cardiovasc Surg. 1999;11:194-200.

29. Tavakkol Z, Gelehrter S, Goldberg CS, Bove EL, Devaney EJ, Ohye RG. Superior durability of SynerGraft pulmonary allografts compared with standard cryopreserved allografts. Ann Thorac Surg. 2005;80:1610-4.

30. Bechtel JF, Gellissen J, Erasmi AW, Petersen M, Hiob A, Stierle U, et al. Midterm findings on echocardiography and computed tomography after RVOT-reconstruction: comparison of decellularized (SynerGraft) and conventional allografts. Eur J Cardiothorac Surg. 2005;27:410-5.

31. Bechtel JF, Stierle U, Sievers HH. Fifty-two months' mean follow up of decellularized SynerGraft-treated pulmonary valve allografts. J Heart Valve Dis. 2008; 17:98-104. 